\title{
Obstetrical risks before and after bariatric surgery
}

\author{
Bogdan MAXIM ${ }^{1}$, Corina GICA ${ }^{1}$, Radu BOTEZATU ${ }^{1,2}$, Anca Maria PANAITESCU ${ }^{1,2}$, \\ Anca Marina CIOBANU ${ }^{1,2}$, Brindusa Ana CIMPOCA-RAPTIS ${ }^{1,2}$, \\ Gheorghe PELTECU ${ }^{1,2}$, Nicolae GICA ${ }^{1,2}$ \\ ${ }^{1}$ Filantropia Clinical Hospital, Bucharest, Romania \\ 2"Carol Davila" University of Medicine and Pharmacy, Bucharest, Romania
}

\begin{abstract}
-
Obesity is defined as a body mass index (BMI) greater than $30 \mathrm{~kg} / \mathrm{m}^{2}$ and it is a major healthcare issue, with an increasing number of people being obese worldwide, including reproductive-aged women. Due to the great impact it has on morbidity and mortality, finding solutions to combat this century's health menace became an issue and a necessity.

Bariatric surgery is nowadays the treatment of choice for severe obesity due to the major weight loss following the procedure and improvements in several health outcomes. But as with all surgical procedures, it can also lead to complications, such as intestinal occlusions, with severe consequences, especially during pregnancy. Moreover, bariatric surgery can favor fetal growth restriction, depending on the type of procedure applied. There are two main types of bariatric surgery, purely restrictive procedures (sleeve gastrectomy, gastric banding) and malabsorptive or mixed procedures (biliopancreatic diversion, gastric bypass). Mixed procedures have been the first choice for many years because of the greater weight loss compared to gastric banding, but they can lead to nutritional deficiencies, with a potential impact on fetal development, causing an increased incidence of small-for-gestational-age fetuses (SGA). Main nutritional deficiencies include iron, vitamin B12, folate, and calcium. On the other hand, pregnant women who underwent bariatric surgery have lower risks of GDM (gestational diabetes mellitus), gestational hypertension and fetal macrosomia.
\end{abstract}

Keywords: bariatric surgery, obesity, pregnancy outcome, fetal growth restriction

\section{BACKGROUND}

The incidence of obesity is increasing rapidly across the world and it has a great impact on morbidity and mortality. Many of these subjects are women at reproductive age, and it is known that morbidly obese women who become pregnant have an increased risk of complications such as gestational diabetes mellitus, gestational hypertension, pre-eclampsia, macrosomia, shoulder dystocia, infectious morbidity, cesarean delivery, postpartum hemorrhage.

Many bariatric surgery procedures exist, the most commonly used being the Roux-en-Y gastric bypass
(RYGB) and the gastric banding. Nowadays laparoscopy is preferred due to its advantages (short recovery time, short hospitalization time, decreased blood loss, pain, and discomfort, fewer wound complication-especially in obese patients). Depending on the type of procedure performed, the mechanism of weight loss is different. Gastric bypass leads to weight loss through a combination of malabsorption and restriction of calories, while gastric banding leads to weight loss only through restriction. This results in slight differences in outcomes, depending on the technique used. Nutritional imbalances resulting from bariatric surgery af- 
TABLE 1. The articles included in the systematic review

\begin{tabular}{|c|c|c|c|c|c|c|c|c|c|c|c|c|c|c|c|c|c|}
\hline Author & $\begin{array}{c}\text { No. of } \\
\text { patients }\end{array}$ & $\begin{array}{c}\text { Mean } \\
\text { age } \\
(y .0)\end{array}$ & \multicolumn{3}{|c|}{$\begin{array}{l}\text { Pre-pregnancy BMI } \\
\left(\mathrm{kg} / \mathrm{m}^{2}\right)\end{array}$} & \begin{tabular}{|c|} 
No. of \\
patients \\
with mal- \\
absoptive \\
proce- \\
dures
\end{tabular} & $\begin{array}{l}\text { No. of } \\
\text { patients } \\
\text { with } \\
\text { purely } \\
\text { restric- } \\
\text { tive pro- } \\
\text { cedures }\end{array}$ & \multicolumn{3}{|c|}{$\begin{array}{l}\text { Interval between } \\
\text { surgery and } \\
\text { delivery (days/ } \\
\text { months/ years }\end{array}$} & \multicolumn{3}{|c|}{$\begin{array}{c}\text { Neonatal birthweight } \\
\text { (g) }\end{array}$} & \multicolumn{2}{|c|}{$\begin{array}{c}\text { SGA } \\
\text { Incidence/ } \\
\text { risk vs non } \\
\text { operated } \\
\text { women }\end{array}$} & \multicolumn{2}{|c|}{$\begin{array}{c}\text { LGA } \\
\text { incidence/ } \\
\text { risk vs non } \\
\text { operated } \\
\text { women }\end{array}$} \\
\hline $\begin{array}{l}\text { Audrey } \\
\text { Chevrot } \\
\text { et al. }\end{array}$ & 139 & $\begin{array}{c}31.7 \pm \\
4.9\end{array}$ & \multicolumn{3}{|c|}{$34.1 \pm 6.0 \mathrm{~kg} / \mathrm{m}^{2}$} & 58 & 81 & \multicolumn{3}{|c|}{38 months } & \multicolumn{3}{|c|}{$3317 \pm 520 \mathrm{~g}$} & \multicolumn{2}{|c|}{$\begin{array}{c}24 \\
\text { (higher) }\end{array}$} & \multicolumn{2}{|c|}{$\begin{array}{c}15 \\
\text { (lower) }\end{array}$} \\
\hline \multirow[t]{2}{*}{$\begin{array}{l}\text { Tuoc Dao } \\
\text { et al. }\end{array}$} & \multirow[t]{2}{*}{34} & \multirow[t]{2}{*}{33} & $\begin{array}{l}\text { Early } \\
\text { group }\end{array}$ & \multicolumn{2}{|c|}{$\begin{array}{l}\text { Late } \\
\text { group }\end{array}$} & \multirow[t]{2}{*}{34} & \multirow[t]{2}{*}{0} & \multirow{2}{*}{\multicolumn{3}{|c|}{$\begin{array}{l}\text { Within the first } \\
\text { year / after }\end{array}$}} & \multirow{2}{*}{\multicolumn{3}{|c|}{$2727 \mathrm{~g}$}} & \multirow{2}{*}{\multicolumn{2}{|c|}{$-\mathrm{NR}-$}} & \multirow{2}{*}{\multicolumn{2}{|c|}{$-\mathrm{NR}-$}} \\
\hline & & & $\begin{array}{c}35 \\
\mathrm{~kg} / \mathrm{m}^{2}\end{array}$ & \multicolumn{2}{|c|}{$\begin{array}{c}28 \\
\mathrm{~kg} / \mathrm{m}^{2}\end{array}$} & & & & & & & & & & & & \\
\hline $\begin{array}{l}\text { Mette } \\
\text { Mandrup } \\
\text { Kjær et al. }\end{array}$ & 355 & 31.4 & \multicolumn{3}{|c|}{$32.4 \mathrm{~kg} / \mathrm{m}^{2}$} & 286 & 57 & \multicolumn{3}{|c|}{629 days } & \multicolumn{3}{|c|}{$3312 \mathrm{~g}$} & \multicolumn{2}{|c|}{$\begin{array}{l}2 \text { times } \\
\text { higher risk }\end{array}$} & \multicolumn{2}{|c|}{$\begin{array}{l}3.3 \text { times } \\
\text { lower risk }\end{array}$} \\
\hline \begin{tabular}{|l|} 
Anne- \\
Solenn \\
Jacamon \\
et al. \\
cardio- \\
vascular \\
disease \\
\end{tabular} & 52 & $\begin{array}{l}31.1 \pm \\
5.0\end{array}$ & \multicolumn{3}{|c|}{$29.4 \pm 6.1 \mathrm{~kg} / \mathrm{m}^{2}$} & 19 & 33 & \multicolumn{3}{|c|}{$3.0 \pm 3.0$ years } & \multicolumn{3}{|c|}{$2960 \pm 545 \mathrm{~g}$} & \multicolumn{2}{|c|}{9 (higher) } & \multicolumn{2}{|c|}{0 (lower) } \\
\hline \multirow{2}{*}{\begin{tabular}{|l|} 
Enrico \\
Facchiano \\
et al
\end{tabular}} & \multirow[t]{2}{*}{36} & 31 & LAGB & & & 17 & 19 & LAGB & LR & GB & & GB & LRYGB & LAGB & LRYGB & LAGB & LRYGB \\
\hline & & & $\begin{array}{c}33.9 \pm \\
5.8 \\
\mathrm{~kg} / \mathrm{m}^{2}\end{array}$ & $\begin{array}{r}32.8 \\
\mathrm{~kg}\end{array}$ & $\begin{array}{l} \pm 5.3 \\
m^{2}\end{array}$ & & & $\begin{array}{c}29.9 \pm \\
21.2\end{array}$ & $\begin{array}{r}24 \\
17\end{array}$ & $\begin{array}{l}5 \pm \\
.3\end{array}$ & & $\begin{array}{l}24 \pm \\
25 \mathrm{~g}\end{array}$ & $\begin{array}{c}2983.5 \\
\pm 478.0 \\
\mathrm{~g}\end{array}$ & 1 & 2 & 2 & 0 \\
\hline $\begin{array}{l}\text { Bruna } \\
\text { Balestrin } \\
\text { et al. }\end{array}$ & 93 & 31.7 & & $29 \mathrm{~kg} / \mathrm{m}$ & & 43 & 50 & $\begin{array}{r}\text { Withi } \\
\text { yea }\end{array}$ & $\begin{array}{l}n \text { the } \\
r / \text { aft }\end{array}$ & $\begin{array}{l}\text { first } \\
\text { er }\end{array}$ & & 3011.5 & & $\begin{array}{r}22(s) \\
\text { lou }\end{array}$ & $\begin{array}{l}\text { lightly } \\
\text { ver) }\end{array}$ & $3(\mathrm{lo}$ & wer) \\
\hline $\begin{array}{l}\text { A. Brön- } \\
\text { nimann } \\
\text { et al. }\end{array}$ & 40 & $\begin{array}{c}29.2 \pm \\
5.5\end{array}$ & & $5.2 \mathrm{~kg} / \mathrm{r}$ & & 40 & 0 & 20.8 & mon & & & $2737 \mathrm{~g}$ & & hig & her & & NR- \\
\hline Atsushi & 24 & 30 & LAGB & LSG & MS & 13 & 11 & LAGB & LSG & MS & LAGB & LSG & MS & hig & gher & & NR- \\
\hline et al & & & $\begin{array}{c}31.2 \\
\mathrm{~kg} / \mathrm{m}^{2}\end{array}$ & $\begin{array}{l}24.8 \\
\mathrm{~kg} / \mathrm{m}^{2}\end{array}$ & $\begin{array}{c}26.3 \\
\mathrm{~kg} / \mathrm{m}^{2}\end{array}$ & & & $28 \mathrm{~m}$ & $26 \mathrm{~m}$ & $18 \mathrm{~m}$ & $3272 \mathrm{~g}$ & $3005 \mathrm{~g}$ & $2664 \mathrm{~g}$ & & & & \\
\hline $\begin{array}{l}\text { Kari } \\
\text { Johansson } \\
\text { et al. }\end{array}$ & 596 & $31 \pm 5$ & 30.3 & $\pm 4.9 \mathrm{k}$ & $/ \mathrm{m}^{2}$ & 582 & 14 & & 1 yea & & & $-\mathrm{NR}-$ & & $92(\mathrm{hi}$ & igher) & $51(\mathrm{l}$ & ower) \\
\hline \begin{tabular}{|l|} 
Emre \\
Günakan
\end{tabular} & 23 & $\begin{array}{c}32.4 \pm \\
0.8\end{array}$ & 29.7 & $\pm 3.8 \mathrm{k}$ & $/ \mathrm{m}^{2}$ & 0 & 23 & & mont & & & $\begin{array}{l}\text { oup } \\
1\end{array}$ & $\begin{array}{l}\text { Group } \\
2\end{array}$ & $2(1$ & $10 \%)$ & & NR- \\
\hline & & & & & & & & & & & $30 €$ & $63 \mathrm{~g}$ & $2883 \mathrm{~g}$ & & & & \\
\hline
\end{tabular}

$B M I$ - body mass index; SGA - small for gestational age; LGA - large for gestational age; NR - not reported; LAGB - laparoscopic adjusted gastric banding; LRYGB - laparoscopic Roux-en-Y gastric bypass; LSG - laparoscopic sleeve gastrectomy; MS - malabsorptive surgery; $m$ - months

fect fetal growth and cause a rise in the incidence of SGA fetuses, this being observed especially in patients operated with malabsorptive or mixed techniques.

Usually, in the first year after the surgery, it is expected that patients lose about $30 \%$ of their excess weight, but most of them will not achieve a normal BMI due to the extreme bodyweight they have before the procedure. At the time of this article, there is no protocol to determine a minimum time between surgery and pregnancy. Recent studies sustain the safety of pregnancy after gastric bypass surgery, with a recommended delay period of 12 to 18 months after the procedure, due to the rapid weight loss phase and catabolic state that can lead to maternal, fetal, or neonatal complications.

As shown in studies, when compared to obese pregnant women, those who underwent bariatric surgery are at lower risk of developing gestational hypertension, gestational diabetes, and fetal macrosomia, mainly because obesity is a risk factor in all of those afflictions. Obesity is widely known for being directly related to infertility in reproductive-aged women. In these cases, bariatric surgery is a successful alternative against obesity when different weight loss strategies were not successful. 


\section{MATERIALS AND METHODS}

A systematic search of the literature was conducted in the database of PubMed, in order to select fulllength articles published in peer-reviewed journals up to 31st of May 2021. The keywords along with respective combinations included in the search strategy were bariatric surgery, gastric banding, gastric bypass, sleeve gastrectomy, laparoscopy, obesity, obesity surgery, body mass index, pregnancy, pregnancy outcome, fetal growth restriction, neonatal birth weight.

\section{RESULTS}

Using the search algorithm based on specific keywords on PubMed, we found 375 relevant articles, published between 1986 and 2021, selecting only the full-text articles, with studies performed on a population of adult females with age ranging from 19-44 years old, published in the last 5 years in trusted journals, written by experts in the field.

The inclusion criteria for the study were at first the keywords used in the search strategy. Furthermore, we included only articles published in the last 5 years, that were guided specifically on the topic at hand, each of them analyzing multiple types of bariatric surgery performed and comparing the obstetrical outcome for each one. We excluded articles older than 5 years, that did not compare types of bariatric surgery and obstetrical outcomes and did not focus on the topic at hand or had significant or clear results. In the final analysis we included 10 articles, published between 2017 and 2021.

\section{DISCUSSION}

The first study analyzed [1] evaluated 139 patients who underwent bariatric surgery, 58 malabsorptive procedures (gastric bypass) and 81 restrictive procedures (72 gastric banding and 9 -sleeve gastrectomy). The mean period between surgery and delivery was 38 months [1]. Study group A (women who underwent bariatric surgery) was compared to control group B (non-operated obese women matched for pre-surgical $\mathrm{BMI})$. In the study group, the mean BMI pre-surgery was $45\left(\mathrm{~kg} / \mathrm{m}^{2}\right)$ and the pre-pregnancy BMI was 34.1 (mean decrease of $11+/-6.8$; relative decrease of $24.4 \%$ ) [1]. The absolute mean decrease in weight was $31 \mathrm{~kg}$. The study group had a bigger gestational weight gain, but a lower incidence of gestational diabetes [1]. Neonatal birth weight was lower in the study group (3317g \pm 520 vs. $3528 \pm 514 \mathrm{~g})$ [1]. A lower ratio of LGA (large for gestational age) and a higher ratio of SGA (small for gestational age) was observed in the study group [1]. Furthermore, depending on the type of sur- gery (malabsorptive vs. restrictive), the mean term birth weight was inferior in the group that had a malabsorptive vs. purely restrictive surgery and non-operated controls matched for prepregnancy BMI [1]. This resulted in a lower incidence of LGA and an incidence of SGA three times higher in the bypass group than in the restrictive group and controls [1]. Gastric bypass seems to be an independent risk factor for fetal growth restriction (FGR) [1]. Fetal growth restriction can be the result of metabolic disorders and can be avoided by supplementing the mother [1]. Usual nutritional deficiencies after gastric bypass are vitamin D, vitamin B12, calcium, iron [1]. The number of cesarean sections was not significantly different from controls, but was high in women who had bariatric surgery [1].

Tuoc Dao et al. [2] selected from a total of 2432 patients undergoing weight loss, only 34 patients who became pregnant after surgery (33 underwent laparoscopic Roux-en-Y gastric bypass and 1 patient had an open procedure) [2]. The study population was divided into 2 groups - the early group (patients that became pregnant in the first 12 months after surgery; $n=21$ ) and the late group (patients that delayed pregnancy for more than 12 months after surgery; $n=13$ ) [2]. Both groups were similar comparing age and BMI. In the early group, there were 5 miscarriages, 1 ectopic pregnan$c y$, and 1 set of twins. The set of twins were the only ones with pre-term birth (born at 35 weeks gestation) and had low birth weight (2325 g, 1786 g) [2]. There were no congenital defects observed at birth [2]. There were 9 vaginal deliveries vs. 6 cesarean sections ( 3 were repeated cesarean sections) [2]. Infertility problems before gastric bypass surgery was observed in 8 patients, while complications during pregnancy, only in one patient with symptomatic cholelithiasis that required hospitalization [2]. After delivery, laparoscopic cholecystectomy was performed [2]. Other complications included preterm labor $(n=1)$, and slight hypertension $(n=1)[2]$. One patient had a mild iron deficiency that was corrected with iron supplements [2]. In the late group, there were 3 sets of twins ( 2 sets of twins were born preterm and had low birth weight (1616-1899 g) [2]. There were 6 vaginal deliveries vs. 7 cesarean sections (one was repeated cesarean section delivery). Four patients had reported difficulty becoming pregnant before their weight-loss surgery [2]. Complications reported during pregnancy were placental abruption $(n=1)$, preterm labor $(n=2)$, preeclampsia $(n=1)$. [2] There was no nutritional imbalance in the late group [2]. In both groups there were no congenital defects observed at birth [2]. No difference in the incidence of preterm labor, preeclampsia, fetal birth weight or number of cesarean sections was found when comparing the two groups [2]. Pregnancy complications after weight-loss surgery and jejunal intestinal bypass included IUGR (intrauterine 
growth restriction), gastrointestinal bleeding, anemia, and neural tube defects [2]. It is advised to take supplements such as vitamin B12, iron, and folate [2]. Pregnancy after Roux-en-Y gastric bypass has no adverse perinatal outcomes according to recent studies [2].

Kjær MM et al. [3] identified 355 women who had 1 or more births after bariatric surgery. Roux en $\mathrm{Y}$ gastric bypass (RYGB) was performed in 286 (83.4\%) women and gastric banding in 57 (16.6\%) women [3]. Children born after maternal bariatric surgery (exposed group) had a lower mean gestational age ( 274 vs. 278 days), lower mean birth weight, lower risk of being LGA (3.3 times lower risk), but had a higher risk of being SGA (2 times higher risk; with even higher risk when analyzing data from women with gastric bypass) [3]. Comparing the groups, no significant difference was found in the rate of preterm birth ( 37 weeks) or birth after 42 weeks, gestational diabetes mellitus, induction of labor, cesarean sections, preeclampsia, postpartum hemorrhage, Apgar score less than 7, admission to neonatal intensive care unit, or in the incidence of perinatal death [3]. Gastric bypass is a more extensive operation and causes a larger weight loss because it acts through food restriction as well as malabsorption (since it bypasses a part of the small intestines) and it may lead to a lack of essential nutrients, vitamin and iron deficiency which may contribute to the risk of SGA [3]. Bariatric surgery improves lipid and glucose metabolism with great results on diabetic women, most of them being cured almost immediately after surgery [3].

Jacamon AS et al. [4] analyzed a population of 52 women with pregnancies occurring after bariatric surgery (exposed group) matched twice with 2 control groups (group A - 104 women matched to exposed women on age, parity and pB-BMI-pre-bariatric BMI; and group $\mathrm{B}-104$ women matched to exposed women on age, parity and pP-BMI - pre-pregnancy BMI) [4]. Sleeve gastrectomy was mainly performed (58.0\%) [4]. The median time between BS and conception was $3.0 \pm$ 3.0 years, with 18 pregnancies (35\%) occurring in the first year after BS. Gestational diabetes was diagnosed in 6 cases in the exposed group (12\%), 46 cases in group $A$ (44\%), and 18 cases in group B (17\%) [4]. The incidence of preeclampsia was $2 \%$ in the exposed group vs. $13 \%$ in group A [4]. The risk of preterm delivery was higher in the exposed group than in group A ( $8 \%$ versus 0 ) and no significant difference for prematurity was found when comparing the groups [4]. Cesarean section rate was higher in operated women [4]. Birth weights were lower in the exposed group ( $2960 \pm 545 \mathrm{~g}$ ) compared to group A (3381 $\pm 735 \mathrm{~g})$ and group B (3310 $\pm 645 \mathrm{~g})$ [4]. There were no LGA infants in the exposed women group $(0 \%$ vs. $13 \%$ group A vs. $8 \%$ group B) [4]. When analyzing the neonatal outcomes, $17 \%$ of newborns from the exposed group were transferred to the NICU compared to $6 \%$ in group $A$ and $8 \%$ in group $B$ [4].
In his paper, Facchiano E et al. studied 42 pregnancies in 36 women who underwent bariatric surgery, with 22 pregnancies (19 women) included in the LAGB group and 20 pregnancies (17 women) included in the LRYGB group [5]. Two miscarriages were noted in the LRYGB group (at 16 and 22 weeks of gestation). When comparing the groups, there was no significant difference between the mean BMI at conception and mean weight gain. The mean gestational age and mean birth weight were 38.7 weeks and $3225 \mathrm{~g}$ in the LAGB group and 38.9 weeks and $2984 \mathrm{~g}$ in the LRYGB group [5]. Two women in the LAGB group had pre-eclampsia and 2 in the LRYGB group had severe anemia (hemoglobin $<10$ $\mathrm{g} / \mathrm{dl})$. When analyzing the way of delivery methods it was noticed 7 cesarean sections in the LAGB group and 8 in the LRYGB group, 1 instrumental delivery in the LAGB group, and 2 in the LRYGB group [5]. As postpartum complications, 2 postpartum hemorrhages were recorded in the LAGB group [5]. In the LRYGB group, 4 minor complications were recorded secondary to the bariatric surgery: 1 case of self-limiting anal bleeding from an anal fissure secondary to chronic constipation, 2 cases of anemia (hemoglobin $<10 \mathrm{~g} / \mathrm{dl}$ ) due to iron deficiency, and 1 case of dumping syndrome in the first trimester [5]. None of these complications required reoperation [5]. No fetal anomalies were noted. The mean birth weight was $3225 \mathrm{~g}$ in the LAGB group vs. $2984 \mathrm{~g}$ in the LRYGB group. There were 2 cases of LGA infants in the LAGB group [5]. There were 3 cases of SGA infants, 1 in the LAGB group vs. 2 in the LRYGB group [5]. Regarding the bariatric procedure complications during pregnancy, it was noted that no patient in the LRYGB experienced gravid vomiting [5]. In the LAGB group, 3 women experienced early gravid vomiting, with 2 of them needing band deflation [5]. Two other patients experienced late vomiting at 28 and 34 weeks, one needing band removal because of band slippage in the third trimester, with no complications for pregnancy after the removal [5]. In 3 cases, gastric banding was deflated systematically at the beginning of pregnancy [5]. There was a total of 5 band deflations and 1 band removal [5]. Nutritional deficiencies observed after LRYGB include calcium, folates, iron, vitamin B1, and fat-soluble vitamins [5]. Another mechanism responsible for vitamin B1 and B9 deficiency is the high frequency of vomiting caused by some types of bariatric surgery [5]. These deficiencies could contribute to serious problems such as neural tube closure defects, especially in LRYGB [5].

In another paper, Balestrin B et al. observed 93 pregnant women who underwent bariatric surgery and 205 obese pregnant women as controls [6]. During pregnancy, the mean weight gain in the post-bariatric group was $10 \mathrm{~kg}$ and $10.3 \mathrm{~kg}$ in the obese group. The time between surgery and pregnancy was less than 
one year in $12.9 \%$ of women $(n=12)$. Roux-en-Y gastric bypass was the procedure of choice in $46.2 \%$ of the cases. Regarding complications during pregnancy, $47.3 \%$ of women in the postbariatric group and $89.3 \%$ of women in the obese group had at least one pregnancy-related complication (preeclampsia, hypertension, diabetes, anemia) [6]. It seems that bariatric surgery was a protective factor against such complications [6]. The pregnancy outcome was similar in both groups and there was no significant difference in Apgar scores (1 and 5 minutes) between the groups or incidence of respiratory distress or fetal malformations [6]. There was a significant difference in mean birth weight between the groups (3011.5 $\mathrm{g}$ in the post-bariatric group vs. $3317.9 \mathrm{~g}$ in the obese group). There was a greater necessity of monitoring in neonatal ICU among newborns from the group of post-bariatric mothers (16.1\% vs. $7.8 \%$ ) [6]. There was a tendency for LGA infants as the mother's BMI increased, as well as a tendency for SGA infants among mothers who had bariatric surgery [6].

Brönnimann $A$ et al. evaluated 40 women that became pregnant within 5 years after bariatric surgery (pregnancy group) [7]. The "non-pregnancy group" was formed out of 247 women who did not conceive within 5 years after RYGB. There was a total of 58 pregnancies observed in 40 women. The mean age at surgery was $29.2 \pm 5.5$ years for the pregnancy group vs. $36.4 \pm 6.3$ years for the non-pregnancy group. Women in the pregnancy group were significantly younger and with heavier weight at the time of surgery [7]. In the pregnancy group, there were 3 adverse events (1\%) represented by pulmonary atelectasis (1), pulmonary embolism (1), and portal venous thrombosis (1) [7]. There was no need for surgical reintervention. There was no statistical difference between the two groups regarding long-term complications (dysphagia, vomiting, abdominal pain, anastomotic ulcers, and reoperation). In the pregnancy group, one gastrojejunal stenosis was identified [7]. From a total of 31 women that needed late reinterventions, 4 were in the pregnancy group, and 27 in the non-pregnancy group, with indications such as internal hernia, umbilical hernia, small bowel obstruction, cholelithiasis, appendicitis [7]. Of a total of 40 first pregnancies, 28 women completed the first pregnancy successfully (two of which were twins). Four spontaneous miscarriages $(11,4 \%$, which is consistent with the $10-20 \%$ miscarriage rate in the general obstetric population), two voluntary terminations of pregnancy, and one stillbirth of a 450-g infant delivered at 22 weeks were noted [7]. Nutritional deficiencies commonly noted after RYGB (iron, vitamin B12, vitamin D, folic acid, and proteins), can lead to fetal complications such as preterm birth, low birth weight, neonatal hypocalcemia, neural tube defect, fetal mental retardation, and materal complications such as osteomalacia [7]. Wom- en who underwent bariatric surgery and became pregnant after the surgery have a higher risk for SGA infants [7]. The mean Apgar scores in this study were above 7. All of these data suggest that pregnancy after RYGB is safe [7].

Watanabe A et al. evaluated 24 women who became pregnant after bariatric surgery [8]. Based on the type of technique applied, 6 women underwent LAGB, 5 LSG, and 13 malabsorptive surgery (MS). In the MS group, hypertension and type 2 diabetes mellitus were completely controlled during prepregnancy, but hypertension was completely resolved in almost $50 \%$ of the women after LAGB and LSG [8]. Anemia was the most frequent complication during pregnancy, especially after MS (69\%), with two patients diagnosed with severe anemia during pregnancy (hemoglobin levels $<8.0 \mathrm{~g} /$ dl) [8]. An important decrease in hemoglobin levels (median $1.9 \mathrm{~g} / \mathrm{dl}$ ) and low serum iron (median 38.5 $\mathrm{mg} / \mathrm{dl}$ ) were present in patients who underwent $\mathrm{MS}$, their median hemoglobin level during pregnancy being the lowest [8]. The mechanisms of anemia are widely known (deficiencies in iron, vitamin B12, and folate) [8]. Maternal anemia is one of the main causes of low birth weight. HELLP syndrome (hemolysis, elevated liver enzymes, lowered platelets) was present in one patient who underwent LAGB but did not have hypertension during prepregnancy [8]. Half of the patients who underwent LAGB still had gestational hypertension after the procedure [8]. The median neonatal birth weight was $3272 \mathrm{~g}$ in LAGB vs. $3005 \mathrm{~g}$ in LSG vs. $2664 \mathrm{~g}$ in MS, with a significant difference between LAGB and MS [8]. No preterm births were noted after any of the surgical techniques [8].

Johansson $\mathrm{K}$ et al. investigated 670 pregnancies that occurred in women who had previously undergone bariatric surgery and for whom presurgery weight was documented [9]. Controls were identified for all but 74 (11\%) of the 670 post-surgery pregnancies. Regarding the bariatric surgery technique, almost 98\% ( $n=582)$ were gastric bypass, $2 \%(n=11)$ were gastric banding, and less than $1 \%(n=3)$ were other procedures [9]. The median period between surgery and delivery was 1.8 years. After surgery, there was a lower risk of LGA infants (8.6\% vs. $22.4 \%$ ) and macrosomia (1.2\% vs. $9.5 \%)$ but an increased risk of SGA infants (15.6\% vs. $7.6 \%)$ [9]. The risk of the combined outcome of stillbirth or neonatal death was $1.7 \%$ in the postsurgery group and $0.7 \%$ in the control [9]. There was no significant difference in the rate of congenital malformations [9]. A higher decrease in BMI was associated with a lower risk of LGA infants and a higher risk of preterm birth [9]. A longer period between surgery and delivery was associated with a higher risk of SGA infants [9].

Günakan $E$ et al. observed that patients who are subjected to bariatric surgery lose weight dramatically 
(up to $30 \%$ ) in the first year [10]. The study group consisted of 23 patients with a total of 20 live births. Two groups of patients were formed, based on the moment of conception: earlier than 12 months after surgery, group 1 and later than 12 months after surgery, group 2. The surgical procedure applied was laparoscopic sleeve gastrectomy (LSG). The number of patients in group 1 was 16 and in group 2 was 7. The mean age was $32.4 \pm 0.8$ years. The mean BMI of patients before sleeve gastrectomy was $46.6 \mathrm{~kg} / \mathrm{m} 2$ and at the time of pregnancy was $29.7 \mathrm{~kg} / \mathrm{m} 2$. The mean weight gain was $6.3 \pm 1.3 \mathrm{~kg}$ [10]. Nine patients (39.1\%) had a history of infertility. The mean period between sleeve gastrectomy and pregnancy was 11 months. No significant differences between groups 1 and 2 in terms of $\mathrm{Hb}$, ferritin, or 25-OH Vit-D levels were noted [10]. Four patients needed intravenous iron therapy, with 3 of those patients in group 1 (gastric intolerance 3 cases and one case of severe anemia, low ferritin level being the main reasons) [10]. There were 7 maternal-fetal complications: 2 patients had GDM, 2 hypertensive disorders (mild preeclampsia), 2 IUGR and 1 preterm delivery [10]. There was a total of 3 miscarriages in the first trimester, with patients who conceived at 2, 15, and 24 months after surgery [10]. There was no significant difference between the groups regarding the fetal birth weights (3063 g vs. $2883 \mathrm{~g}$ ). The SGA birth rate was $10 \%$ ( 2 cases) of the total of patients. Nine patients (45\%) were delivered by cesarean section ( 8 for prior cesarean sections and 1 for fetal distress) [10]. One patient with IUGR and two patients with gestational hypertension were subjected to induction of labor resulting in vaginal delivery [10]. No surgical site infection or episiotomy dehiscence occurred [10].

\section{CONCLUSIONS}

It is widely known that obesity-related maternal-fetal complications rates such as hypertension, preeclampsia, gestational diabetes, and macrosomia, decrease significantly after bariatric surgery. Data showed that a shorter period between surgery and conception did not significantly affect the obstetric and neonatal outcomes. A waiting period of at least 12 months is rec- ommended because pregnancy in this catabolic period and stopping the weight loss process, are not advisable.

Bariatric surgery patients are in a negative nutritional balance, deficiencies in iron, calcium, vitamin $B$, vitamin $D$ being frequent after certain types of surgery, thus requiring supplementation in order to avoid the consequences of such deficiencies. This can increase the risk of delivery SGA infants, especially in malabsorptive procedures. The smaller surface area of the stomach and a short healing period may lead to intolerance for oral supplements, so intravenous supplementation remains an option for these patients.

Regarding the surgical procedures, the most frequently used are Roux-en-Y gastric bypass (malabsorptive procedure) and gastric banding (restrictive procedure). Laparoscopic variants of these procedures are preferred nowadays because of multiple advantages they have over the classic procedures (short recovery time, short hospitalization time, decreased blood loss, pain, and discomfort, fewer wound complication, especially in obese patients).

Regarding complications after bariatric surgery, small bowel obstruction is the main health issue, with life-threatening implications. Small bowel obstruction results from volvulus, intussusception, and internal hernias. Pregnancy itself contributes to these complications, especially to internal hernias, due to increased intra-abdominal pressure and small bowel displacement caused by the expansion of the uterus. No severe complications or maternal deaths were observed.

Obesity is directly related to reduced fertility. In reproductive-aged women weight loss improves fertility rates. In these cases, bariatric surgery is a successful alternative against obesity when different weight loss strategies were not successful. Although effective, bariatric surgery should not be considered a primary solution for infertility.

The rate of cesarean sections did not significantly differ from controls in any of the studies but remain high in women who had bariatric surgery. In conclusion, in recent studies, no significant differences in pregnancy outcomes were found, sustaining the safety of pregnancy after bariatric surgery.

Conflict of interest: none declared Financial support: none declared

\section{REFERENCES}

1. Chevrot A, Kayem G, Coupaye M, Lesage N, Msika S, Mandelbrot L. Impact of bariatric surgery on fetal growth restriction: experience of a perinatal and bariatric surgery center. Am J Obstet Gynecol. 2016 May;214(5):655.e1-7.
2. Dao T, Kuhn J, Ehmer D, Fisher T, McCarty T. Pregnancy outcomes after gastric-bypass surgery. Am J Surg. 2006 Dec;192(6):762-6.

3. Kjær MM, Lauenborg J, Breum BM, Nilas L. The risk of adverse pregnancy outcome after bariatric surgery: a nationwide register- based matched cohort study. Am J Obstet Gynecol. 2013 Jun;208(6):464.e1-5.

4. Jacamon AS, Merviel P, Herrmann S, Pan-Petesch B, Lacut K, Thereaux J. Outcomes of pregnancy after bariatric surgery: results of a French matched-cohort 
study. Surg Obes Relat Dis. 2020

Sep;16(9):1275-1282.

5. Facchiano $E$, lannelli $A$, Santulli $P$, Mandelbrot L, Msika S. Pregnancy after laparoscopic bariatric surgery: comparative study of adjustable gastric banding and Roux-en-Y gastric bypass. Surg Obes Relat Dis. 2012 Jul-Aug;8(4):429-33.

6. Balestrin B, Urbanetz AA, Barbieri MM, Paes A, Fujie J. Pregnancy After Bariatric Surgery: a Comparative Study of Post-Bariatric
Pregnant Women Versus Non-Bariatric Obese Pregnant Women. Obes Surg. 2019 Oct;29(10):3142-3148.

7. Brönnimann A, Jung MK, Niclauss N, Hagen ME, Toso C, Buchs NC. The Impact of Pregnancy on Outcomes After Bariatric Surgery. Obes Surg. 2020 Aug;30(8):30013009.

8. Watanabe A, Seki Y, Haruta H, Kikkawa E, Kasama K. Maternal impacts and perinatal outcomes after three types of bariatric surgery at a single institution. Arch Gynecol Obstet. 2019 Jul;300(1):145-152.

9. Johansson K, Cnattingius S, Näslund I, Roos N, Trolle Lagerros Y, Granath F, Stephansson O, Neovius M. Outcomes of pregnancy after bariatric surgery. N Engl J Med. 2015 Feb 26;372(9):814-24.

10. Günakan E, Buluş $H$, Tohma YA. Early pregnancy after bariatric surgery: a single-institute preliminary experience. Turk J Med Sci. 2020 Feb 13;50(1):171-176. 